\title{
The cases with opportunistic infections among HIV patients in Indonesia 2011
}

\author{
Roselinda Rusli', Vivi Setiawaty \\ From Abstracts from International Symposium HIV and Emerging Infectious Diseases 2014 \\ Marseille, France. 21-23 May 2013
}

\section{Background}

Human Immunodeficiency Virus (HIV) reduces the ability of person's immune system to combat infection from microorganism such as Tuberculosis, Herpes simplex, Candida, Toxoplasma. Some of these microorganism are normal flora and usually do not generate a serious disease in healthy people, therefore these infections are known as opportunistic infections (OIs). The OI by tuberculosis is the most common cause of death for people infected with HIV worldwide. Since the OIs are not well recorded in Indonesia, in 2011 we conducted study in seven provinces to identify the incidence of OIs among HIV patients.

\section{Method}

The cross sectional study was conducted in several hospitals that has voluntary counseling test (VCT) clinic. The respondents were HIV patients who visited VCT clinics in seven provinces (North Sumatera, West Sumatera, Riau Islands, South Sulawesi, North Sulawesi, Maluku, and Papua) by purposive sampling in 2011. There were 490 respondents included in this study. The statistical analyses were completed using STATA 9.0 version.

\section{Results}

From the study we found several OI from HIV patients. 379 out of 490 respondents reported OIs. Among OIs patients, Tuberculosis, Candidiasis and Diarrhea were the most common OIs with Tuberculosis as the leading cause of OIs. There were 238 out of 490 (48.6\%) infected by Tuberculosis, 202 out of 490 (41.2\%) with Candidiasis and 98 out of 490 (20\%) with diarrhea. Moreover, we also found Dermatitis, Anemia, Lymphadenopathy, Hepatitis C, Herpes Zoster, Toxoplasmosis, Kaposi's sarcoma, Steven-Johnson Syndrome, Morbili, Cirrhosis Hepatis, Rheumatic Lupus and Cryptococcus Meningitis as OIs.

Center for Biomedical and Basic Technology of Health, NIHRD, Jakarta, Indonesia 